\title{
A Novel Population of Phytophthora, Similar to P. infestans, Attacks Wild Solanum Species in Ecuador
}

\author{
M. E. Ordoñez, H. R. Hohl, J. A. Velasco, M. P. Ramon, P. J. Oyarzun, \\ C. D. Smart, W. E. Fry, G. A. Forbes, and L. J. Erselius
}

First, third, fourth, fifth, eighth, and ninth authors: International Potato Center (CIP), P.O. Box 17-21-1977, Quito, Ecuador; second author: Tobelgasse 10, CH-8126 Zumikon, Switzerland; and sixth and seventh authors: Department of Plant Pathology, 334 Plant Science, Cornell University, Ithaca, NY 14853.

Accepted for publication 17 October 1999.

\begin{abstract}
Ordoñez, M. E., Hohl, H. R., Velasco, J. A., Ramon, M. P., Oyarzun, P. J., Smart, C. D., Fry, W. E., Forbes, G. A., and Erselius, L. J. 2000. A novel population of Phytophthora, similar to P. infestans, attacks wild Solanum species in Ecuador. Phytopathology 90:197-202.

Twenty-six isolates of a Phytophthora population from two wild solanaceous species, Solanum tetrapetalum $(n=11)$ and S. brevifolium $(n=$ 15), were characterized morphologically, with genetic and phenotypic markers, and for pathogenicity on potato and tomato. Based on morphology, ribosomal internal transcribed spacer region 2 (ITS2) sequence, and pathogenicity, all isolates closely resembled $P$. infestans and were tentatively placed in that species. Nonetheless, this population of Phytophthora is novel. Its primary host is neither potato nor tomato, and all isolates had three restriction fragment length polymorphism (RFLP) bands (probe RG57) and a mitochondrial DNA haplotype that have not been reported for $P$. infestans. All the isolates were the A2 mating type when

tested with a $P$. infestans A1 isolate. The A2 mating type has not been found among isolates of $P$. infestans from potato or tomato in Ecuador. Geographical substructing of the Ecuadorian A2 population was detected. The three isolates from the village of Nono, identical to the others in all other aspects, differed by three RFLP bands; those from Nono lacked bands 10 and 16, but possessed band 19. Most of the Ecuadorian A2 isolates were nonpathogenic on potato and tomato, but a few caused very small lesions with sparse sporulation on necrotic tissue. Cluster analysis of multilocus genotypes (RFLP, mating type, and two allozymes) dissociated this A2 population from genotypes representing clonally propagated populations of $P$. infestans worldwide. The current hypotheses for the historical global movements of $P$. infestans do not satisfactorily explain the origin or possible time of introduction into Ecuador of this A2 population. Assuming the population is $P$. infestans, its presence in Ecuador suggests either a hitherto unreported migration of the pathogen or an indigenous population that had not previously been detected.
\end{abstract}

Both the A1 and A2 mating types of the potato late blight pathogen Phytophthora infestans (Mont.) de Bary occur in relatively equal frequencies in central Mexico, the organism's purported center of origin $(19,24)$. Only the A1 mating type was found outside Mexico until the 1980s, when the A2 mating type was detected in Europe (22). Furthermore, most evidence indicates that, until the $1980 \mathrm{~s}$, most populations of $P$. infestans outside North America belonged to the clonal lineage US-1, which is the A1 mating type (15). Since the 1980s, new clonal lineages and sexual populations with both the A1 and A2 mating types have been found in different potato-growing regions of the world (13).

Mutation within A1 clonal lineages was proposed as the origin of some A2 genotypes found outside Mexico (23), but subsequent genetic similarity analyses showed that these A2 genotypes were not related to the A1 genotypes with which they coexist geographically (16). The simplest interpretation of these results is that A2 genotypes occurring outside Mexico have not resulted from mutation, but have been introduced (16), probably on infected potato tubers (12) or on tomato fruits or plantlets (13).

Much discussion about the origins and migrations of $P$. infestans can be found in several recent reviews $(1,12,13)$. This information, however, is based primarily on what is known about isolates from potato and, to a lesser extent, tomato. At this time, little is known about the genetic makeup of populations of $P$. infestans (or closely related species) that attack other solanaceous hosts, although

Corresponding author: G. A. Forbes; E-mail address: forbes@cip.org.ec

Publication no. P-1999-1223-01R

(c) 2000 The American Phytopathological Society some of these hosts such as Solanum muricatum Aiton and S. betaceum (Cav.) Sendtner (formerly in the genus Cyphomandra) are cultivated crops and others have been evaluated as sources of resistance to $P$. infestans (4).

Genetic characterization of the populations of $P$. infestans and related species attacking alternative hosts could give new insight into the biology and life history of this important genus of plant pathogens. For example, all seven isolates of Phytophthora species collected in 1995 from several wild solanaceous plants in Ecuador were designated $P$. infestans, based on morphology, and subsequently determined to be the A2 mating type (25). This was unexpected, because the A2 mating type has not been found on potato or tomato in Ecuador, even after relatively recent and extensive sampling $(10,25)$. If the A2 mating type of $P$. infestans had been introduced into Ecuador on potato or tomato since the 1980s, it is unclear why it would have disappeared from populations attacking these crops, while remaining in high frequency in a population attacking wild hosts.

When the A2 isolates from wild hosts in Ecuador were initially reported (25), nothing was known about their genetic relatedness to populations of $P$. infestans currently found on potato and tomato in Ecuador or elsewhere. Furthermore, it was not known whether the A2 isolates were pathogenic on these commercial hosts. In this study, we used neutral markers to compare the original seven A2 isolates and 19 additional isolates subsequently collected with known genetic marker information for potato and tomato populations of $P$. infestans in Ecuador and elsewhere. We used this information to test the hypothesis that this A2 population was introduced into Ecuador by one of the previously described migrations of $P$. infestans. 


\section{MATERIALS AND METHODS}

Sampling and isolation of the pathogen. Twenty-six singlelesion isolates were collected at four locations near Quito, the capital city of Ecuador (Table 1). All four locations are within the zone of potato production and are of similar elevation (between 2,400 and 2,700 meters above sea level) and ecological conditions. Nono, Calacali, and Pululahua are all on the western slope of the Andes, several kilometers northwest of Quito. San Jose de Minas is also on the western slope, but about $40 \mathrm{~km}$ north of Quito. Two or three different sites at least $100 \mathrm{~m}$ apart were sampled within each location. The diseased plants were identified as $S$. brevifolium $\mathrm{H}$. \& B. ex Dun. and S. tetrapetalum Rusby based on published descriptions (5). These species are woody vines belonging to the series Apendiculata and grow under trees, often climbing up trunks, branches, and fence posts.

Collections were carried out during three consecutive years, starting in 1995. First attempts at isolating the pathogen from leaf lesions with potato tuber slices (25) were unsuccessful, because the pathogen grew very poorly on potato tuber tissue. Isolates ultimately were obtained in the following manner. A small piece of leaf tissue from the edge of a sporulating lesion was cut out and surface-sterilized for 1 to $3 \mathrm{~min}$ with a $0.5 \%$ hypochlorite solution, rinsed in sterile distilled water, and then plated on SEL-A1, a selective medium (21). The petri dishes were kept at $18^{\circ} \mathrm{C}$ in the dark until hyphal growth was visible. Agar plugs containing young hyphae were then transferred to rye B (3) or $10 \%$ clarified V8 juice agar. Mating type was determined for all isolates as described previously (25).

Phenotypic description. Isolates were compared for sporangial length and width, pedicel length, and form of the papilla. The sporangia were either washed from the plates with distilled water or a piece of approximately $1 \mathrm{~cm}^{2}$ of agar culture was cut out and inverted several times into $0.1 \mathrm{ml}$ of distilled water on a glass slide. Between 60 and 300 sporangia from 3- to 5-week-old cultures on rye $B$ (occasionally SEL-1A medium) were measured for each isolate using light microscopy and video image analysis. Pedicel length was measured with an ocular micrometer.

Isozyme electrophoresis. Isozyme electrophoresis for the enzymes glucose-6-phosphate isomerase ( Gpi) and peptidase (Pep) was done on starch gels as described previously (27) and on polyacrylamide gels (polyacrylamide gel electrophoresis [PAGE]). PAGE was done using 1-mm-thick $7.5 \%$ gels with $25 \mathrm{mM}$ Tris-0.19 M glycine at $\mathrm{pH} 8.8$ as a separating gel and electrode buffer. Bands were clearer when a $1-\mathrm{cm}$ stacking gel $(2.5 \%$ acrylamide- $0.06 \mathrm{M}$ Tris-HCl, $\mathrm{pH}$ 6.7) was used (6). PAGE gels were run with a constant current of $5 \mathrm{~mA}$ for $1 \mathrm{~h}$, after which the current was increased to $10 \mathrm{~mA}$. Voltage rose continually throughout, from about 50 to $280 \mathrm{~V}$. Electrophoresis was terminated when the bromophenol blue dye reached the bottom of the gel, about $16 \mathrm{~cm}$. Allozyme phenotypes were scored as described previously (27) and represent the mobilities of the enzyme alleles relative to an allele designated as 100. A US-6 isolate with a recorded $92 / 100$ banding pattern on starch from the $P$. infestans collection at Cornell University was used for comparison.

DNA extraction. Isolates were grown for 8 to 10 days at $18^{\circ} \mathrm{C}$ in clear pea broth that was made by autoclaving $120 \mathrm{~g}$ of fresh or

TABLE 1. Isolates of a Phytophthora population collected from two wild Solanum species in the highlands near Quito, Ecuador, between 1995 and 1997

\begin{tabular}{lcclc}
\hline Host & $\begin{array}{c}\text { No. of } \\
\text { isolates }\end{array}$ & $\begin{array}{c}\text { Year } \\
\text { collected }\end{array}$ & \multicolumn{1}{c}{ Location } & $\begin{array}{c}\text { RFLPa } \\
\text { genotype }\end{array}$ \\
\hline S. brevifolium & 4 & 1995 & Pululahua & EC-2 \\
S. brevifolium & 1 & 1996 & Pululahua & EC-2 \\
S. tetrapetalum & 9 & 1996 & Calacali & EC-2 \\
S. brevifolium & 7 & 1997 & Calacali & EC-2 \\
S. brevifolium & 3 & 1997 & Nono & EC-2.1 \\
S. tetrapetalum & 2 & 1997 & San Jose de Minas & EC-2 \\
\hline
\end{tabular}

${ }^{\text {a }}$ RFLP = restriction fragment length polymorphism. frozen peas in 1 liter of water. The peas were removed and the broth autoclaved a second time prior to use. The mycelium was harvested by vacuum filtration, frozen at $-20^{\circ} \mathrm{C}$ for a few hours, and then lyophilized. Lyophilized mycelium was ground with a mortar and pestle with liquid nitrogen or by using a small amount of sand. DNA was extracted according to a miniprep version of a previously published technique (7). One milliliter of preheated $\left(60^{\circ} \mathrm{C}\right)$ extraction buffer $(0.05 \mathrm{M}$ EDTA; $0.1 \mathrm{M}$ Tris, $\mathrm{pH} 8.0 ; 0.5 \mathrm{M}$ $\mathrm{NaCl} ; 0.7 \% \beta$-mercaptoethanol; and $0.25 \%$ sodium dodecyl sulfate) was added to $35 \mathrm{mg}$ of ground lyophilized tissue and incubated for $1 \mathrm{~h}$ at $65^{\circ} \mathrm{C}$. After that, $333 \mu \mathrm{l}$ of $5 \mathrm{M}$ potassium acetate was added, and the tubes were shaken vigorously and placed in crushed ice for $20 \mathrm{~min}$. They were then centrifuged for $10 \mathrm{~min}$ at $16,000 \times g(14,000 \mathrm{rpm})$ and the supernatant collected in a new tube. DNA was precipitated with $800 \mu \mathrm{l}$ of isopropanol, left on ice for $1 \mathrm{~h}$, and centrifuged at $16,000 \times g(14,000 \mathrm{rpm})$ for $5 \mathrm{~min}$. The supernatant was poured off and the pellet air-dried for $1 \mathrm{~h}$. The pellet was dissolved in $100 \mu \mathrm{l}$ of Tris-EDTA (TE; $10 \mathrm{mM}$ Tris- $\mathrm{HCl}$, $\mathrm{pH} 8.0$, and $1 \mathrm{mM}$ EDTA) and then treated with $1 \mu \mathrm{l}$ of RNAase $(10 \mathrm{mg} / \mathrm{ml})$ for $1 \mathrm{~h}$ at $37^{\circ} \mathrm{C}$. For restriction fragment length polymorphism (RFLP) analysis, the DNA was dissolved in $700 \mu \mathrm{l}$ of TE, reprecipitated with $75 \mu \mathrm{l}$ of $3 \mathrm{M}$ sodium acetate and $500 \mu \mathrm{l}$ of isopropanol, left on ice for $2 \mathrm{~min}$, and then centrifuged for $5 \mathrm{~min}$ at a relative centrifugal force of $16,000 \times g(14,000 \mathrm{rpm})$. The pellet was air-dried for $1 \mathrm{~h}$, dissolved in TE, and then treated with $1 \mu \mathrm{l}$ of RNAase $(10 \mathrm{mg} / \mathrm{ml})$ for $1 \mathrm{~h}$ at $37^{\circ} \mathrm{C}$. DNA was compared visually for quality and concentration with a DNA mass ladder by electrophoresis on a $1 \%$ agarose gel with Tris-borate-EDTA buffer (TBE; 0.045 M Tris-borate and 0.001 M EDTA, pH 8.0).

Ribosomal DNA (rDNA) internal transcribed spacer region 2 (ITS2). The ITS2 of the rDNA of $P$. infestans can be amplified using polymerase chain reaction (PCR) and the specific primers ITS3 and PINF2 (28). DNA from all the A2 isolates was amplified using these primers and a template of about $10 \mathrm{ng}$ of DNA as described previously (28). In addition, the ITS2 of six isolates, one each from the six separate collection events (Table 1), were cloned using the Invitrogen Original TA Cloning Kit (Invitrogen Corp., Carlsbad, CA) according to the manufacturer's instructions. The cloned DNA region was purified using the Wizard Plus Minipreps DNA Purification System (Promega Corp., Madison, WI) as recommended by the manufacturer. Plasmids containing inserts were digested with EcoRI and the products separated on a $1 \%$ agarose gel with Tris-acetate-EDTA buffer $(0.04 \mathrm{M}$ Tris-acetate and $0.001 \mathrm{M}$ EDTA, $\mathrm{pH}$ 8.0). The size of the insert was compared with that of the amplified PCR product.

The cloned ITS2 of the rDNA of all six isolates was then sequenced using the dsDNA Cycle Sequencing System (Gibco BRL, Gaithersburg, MD) according to the manufacturer's instructions. The radiolabeled products were resolved on a $6 \%$ polyacrylamide denaturing gel that was then dried and visualized by autoradiography. These sequences were then aligned with the sequences of 14 other species of Phytophthora to identify any dissimilar nucleotides. Sequencing was done using the Clustal method of MegAlign (DNASTAR Inc., Madison, WI).

Mitochondrial DNA (mtDNA) haplotypes. DNA of each isolate was amplified using primers designed for specific regions of the mitochondrial genome of $P$. infestans (20). Digestion of the amplified regions with the restriction enzymes $C f o \mathrm{I}, M s p \mathrm{I}$, and EcoRI yields band patterns by which the isolates can be classified into four different haplotypes: Ia, Ib, IIa, and IIb $(2,20)$.

For PCR, the final concentrations of the master mix were $0.325 \mu \mathrm{M}$ of each forward and reverse primer, $2.5 \mathrm{mM} \mathrm{MgCl}_{2}, 100 \mu \mathrm{M}$ dNTPs, 1.5 units of $T a q$ polymerase, and 4 ng of template DNA. PCR was performed on a PTC-200 Peltier Thermal Cycler (MJ Research, Inc., Watertown, MA) with the following temperature profile: $94^{\circ} \mathrm{C}$ for $1 \mathrm{~min} ; 35$ cycles of $92^{\circ} \mathrm{C}$ for $30 \mathrm{~s}, 55^{\circ} \mathrm{C}$ for $30 \mathrm{~s}$, and $72^{\circ} \mathrm{C}$ for $1 \mathrm{~min}$; and a final extension of $72^{\circ} \mathrm{C}$ for $5 \mathrm{~min}$. Eight microliters of the amplified product was digested with 1 unit of $C f o$ I when ampli- 
fication was done with primer set 1 , with 1 unit of MspI when primer set 2 was used, and with 1 unit of EcoRI when primer sets 3 and 4 were used. The digested products were then run on a $2 \%$ agarose gel in TBE buffer at $10 \mathrm{~V} / \mathrm{cm}$ and visualized with ethidium bromide under UV light.

RG57 DNA fingerprints. RFLP fingerprints were obtained for all isolates using the moderately repetitive probe RG57 (17). Two micrograms of DNA from each isolate was digested with EcoRI for $24 \mathrm{~h}$ and then separated on 0.7 or $0.8 \%$ agarose gels $(56 \mathrm{~V}, 20 \mathrm{~mA})$ for 24 to $45 \mathrm{~h}$ in $1 \times \mathrm{TBE}$. Hybridization and detection were done using the nonradioactive kit ECL (Amersham, Inc., Buckinghamshire, United Kingdom) according to the manufacturer's instructions.

Cluster analysis. Gpi, Pep, and mating type data were combined with RFLP fingerprints as described previously (11) to create multilocus genotypes. Using cluster analysis, multilocus genotypes of isolates from $S$. brevifolium and $S$. tetrapetalum were compared with published genotypes of $P$. infestans taken from a global marker database (11). Data analyses and presentation of results were as described previously (11).

Metalaxyl resistance. Isolates were tested for resistance to 5 and $100 \mu \mathrm{g}$ of metalaxyl per $\mathrm{ml}$ in $10 \%$ unclarified V8 medium and classified as resistant, intermediate, or sensitive. Conditions of the test and criteria for classification were described previously (10).

Pathogenicity. Each isolate was inoculated on detached leaflets of potato, tomato, and $S$. brevifolium or $S$. tetrapetalum. An isolate from potato or tomato was included for comparison. Potato and tomato leaflets came from 8- to 12-week-old plants grown in the greenhouse, while leaflets from $S$. brevifolium or $S$. tetrapetalum were collected from plants growing near the experiment station of the International Potato Center in Quito, Ecuador. Potatoes used in these tests included four tetraploid accessions of $S$. tuberosum (cvs. Pimpernel, Alpha, Uvilla, and Yungay), which are free of known R genes, and four accessions of diploid $S$. phureja from the Ecuadorian national collection (BOM540, Phu644, SOL059, and HSO101), also free of known R genes. Isolates were inoculated on three of the following tomato cultivars: Flora Dade, FMX-93, Carib, and Heat, which were all free of known major genes for resistance (Ph genes).

Inoculum of each isolate was produced on leaflets from its primary host, although $S$. brevifolium and $S$. tetrapetalum were used interchangeably. Sporangia were washed off the leaves and left at $4^{\circ} \mathrm{C}$ for $1 \mathrm{~h}$ to induce zoospore release. One $10-\mu \mathrm{l}$ drop of zoospore suspension (approximately $2 \times 10^{4}$ zoospores per $\mathrm{ml}$ ) from each isolate was put on either side of the midrib of the abaxial surface of the leaflets to be tested. Four leaflets of each host-byisolate combination were inoculated. The leaflets were placed in the lids of inverted petri dishes containing water agar in the base (two leaflets per dish) and incubated for 10 days at $18^{\circ} \mathrm{C}$ with $14 \mathrm{~h}$ of light per day. Symptoms were recorded after 7 and 10 days of incubation. In some cases when lesions did form, lesion diameters were measured as described previously (25) and compared with the lesions produced by the control isolates.

\section{RESULTS}

All 26 isolates from S. brevifolium and S. tetrapetalum fit the phenotypic description of the $P$. infestans A2 mating type, producing abundant oospores when paired with the A1 mating type tester, but not with the A2 tester. All 26 isolates had deciduous, semipapillate sporangia and a small ( 2 to $3 \mu \mathrm{m}$ ) pedicel. Sporangia had a mean length of $26.9 \mu \mathrm{m}$ and a mean width of $16.2 \mu \mathrm{m}$, which, although relatively small, fall within the range for $P$. infestans (9).

The rDNA ITS2 characterization also supported the hypothesis that the A2 isolates from $S$. brevifolium and $S$. tetrapetalum are $P$. infestans or are very closely related. We obtained an amplified product of approximately $465 \mathrm{bp}$ for all isolates, which corresponds to previously published results for $P$. infestans and the closely related species $P$. mirabilis and $P$. phaseoli (28). The ITS2 sequences were also identical to those reported for $P$. infestans, which is identical to that of $P$. mirabilis (C. D. Smart, unpublished data).

Other molecular markers indicated that this A2 Ecuadorian population is different from $P$. infestans found on potato and tomato in Ecuador. For example, all A2 isolates had the Pep 100 allele, but also an allele that in our analysis had a relative mobility of 76 on starch and 81 with PAGE (Fig. 1). The US-6 isolate banding pattern was approximately $92 / 100$ on starch, as expected, but was measured as $88 / 100$ with PAGE (Fig. 1). An allele with a mobility of 78 on starch has been described (11), but we were unable to obtain a representative isolate for comparison. Since electrophoretic running conditions may change mobilities, we do not know if the Pep allele we measured for the Ecuadorian A2 population is novel or is the same as that reported earlier as 78. In either case, the allele we measured does not occur in populations attacking potato or tomato in Ecuador (26).

The Gpi banding pattern of all A2 isolates appeared to be 100/100 on starch ( $\mathrm{pH}$ 6.0), which differs from the predominant genotypes of $P$. infestans that attack potato and tomato in Ecuador (26).

Assessment with the RFLP probe RG57 further differentiated this population from those attacking potato and tomato in Ecuador and also indicated that it is novel relative to populations of $P$. infestans that have been reported thus far $(11,13)$. For example, all Ecuadorian A2 isolates had three bands that have not been described for P. infestans (Fig. 2). We have named these bands 1a, 8a, and 20a, following the precedent of other authors (8). The three isolates from the village of Nono, which was the complete sample from that site, had the novel bands but differed from the other Ecuadorian A2 isolates at three other loci (Fig. 2). Nono isolates lacked bands 10 and 16, but possessed band 19. Bands 10, 16, and 19 have been reported for $P$. infestans (11).

Cluster analysis (Fig. 3) of a multilocus genotype consisting of RFLP, allozyme, and mating type information demonstrated that both A2 genotypes from $S$. brevifolium and $S$. tetrapetalum are quite distinct from any previously published genotypes associated with clonally propagated populations of $P$. infestans (11). The new genotypes from $S$. brevifolium and $S$. tetrapetalum have been named EC-2 for the most common one and EC-2.1 for the one from Nono, according to a proposed nomenclature $(11,14)$.

All isolates from $S$. brevifolium and $S$. tetrapetalum were of the same mtDNA haplotype, but this haplotype is distinct from those reported for $P$. infestans $(2,20)$. Amplification with each of the four primer sets produced a band that corresponded to published results for $P$. infestans (20). After digestion, however, differences were detected between the Ecuadorian A2 isolates and described $P$. infestans haplotypes for two of the amplification products. With primer sets 1 and 3, the Ecuadorian A2 isolates were characterized as haplotype I ( $\mathrm{a}$ or b). Nonetheless, amplification with primer set 4 and digestion with EcoRI produced a novel two-band pattern that is not consistent with published results for known haplotypes of $P$. infestans. One of these bands comigrated with the 209-bp

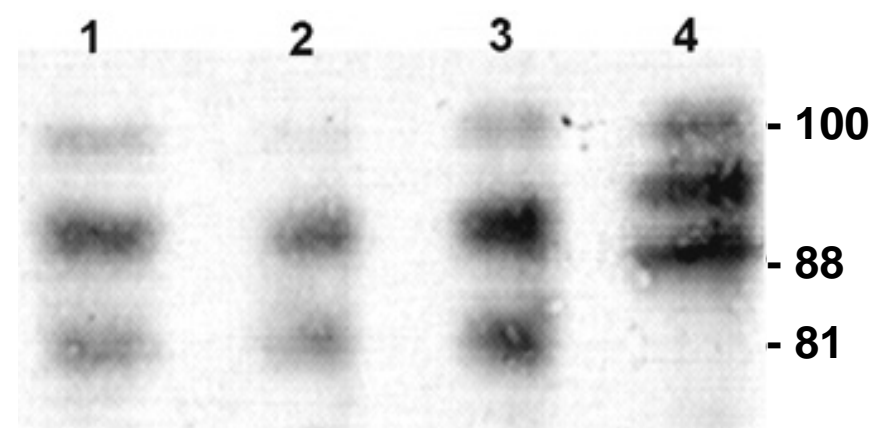

Fig. 1. Peptidase (Pep) profiles from polyacrylamide gel electrophoresis of Ecuadorian A2 isolates of a Phytophthora population isolated from Solanum brevifolium (lanes 1 and 2) and S. tetrapetalum (lane 3) and a US-6 genotype of $P$. infestans (lane 4). Relative mobilities were 81/100 for the Ecuadorian A2 isolates and 88/100 for US-6. 


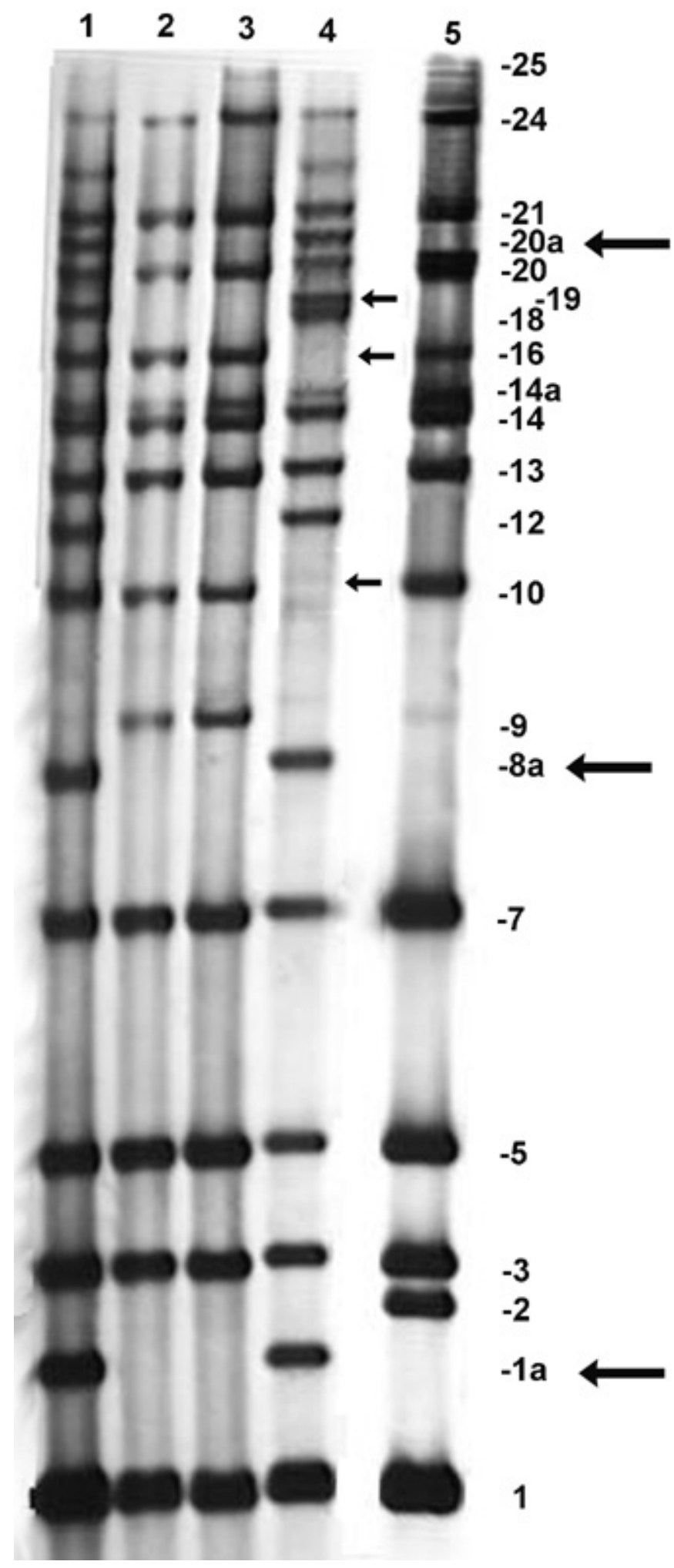

Fig. 2. Restriction fragment length polymorphism genotypes (probe RG57) characteristic of two clonal lineages of Phytophthora infestans (US-1 and EC-1) and a Phytophthora population (EC-2 and EC-2.1), all found in Ecuador. Lane 1, EC-2; lanes 2 and 3, US-1; lane 4, EC-2.1 (a genotype from the village of Nono belonging to the EC-2 clonal lineage); and lane 5, EC-1. In Ecuador, genotypes EC-2 and EC-2.1 are found on the wild hosts Solanum brevifolium and S. tetrapetalum, EC-1 is found on potato, and US-1 is found on tomato. Arrows on lane 4 identify differences between the Nono EC-2.1 genotype and the EC-2 genotype in lane 1. Arrows on numbers indicate bands found in all EC-2 and EC-2.1 isolates that have not yet been reported for $P$. infestans. The band numbering system on the right was established previously (17). band characteristic of haplotypes Ia and $\mathrm{Ib}$ (20), but the other, of approximately $750 \mathrm{bp}$, appeared to be a long fragment that included the 387- and 361-bp fragments that also characterize haplotypes Ia and Ib (20). Therefore, we conclude that the Ecuadorian A2 isolates lack an EcoRI restriction site that characterizes haplotypes Ia and Ib. Using primer set 4 and EcoRI, haplotypes IIa and IIb have two bands of 596 and 361 bp (20), which is also different from Ecuadorian A2 isolates.

Primer set 2 also gave novel banding patterns. After amplification and digestion with $\mathrm{MspI}$, all Ecuadorian A2 isolates had a fragment that corresponds to the 720-bp fragment of haplotypes Ia, IIa, and IIb (20). However, unlike Ia, IIa, and IIb, the Ecuadorian A2 haplotype had two additional bands, a bright one with approximately $125 \mathrm{bp}$ and another fainter band with approximately $100 \mathrm{bp}$ (Fig. 4). Since the amplification product using primer set 2 corresponds in size (approximately $970 \mathrm{bp}$ ) to that published previously, and fragments of 720 and 100 bp were detected, we expected to find one or more additional fragments that would add up to approximately $250 \mathrm{bp}$. Therefore, we deduced that the bright 125-bp band probably consists of two fragments of similar size. The banding pattern of the Ecuadorian A2 isolates using primer set 2 also differs from that published for haplotype Ib (20). For these reasons, the haplotype of the Ecuadorian A2 isolates is novel and cannot easily be classified using the described system (2).

Pathogenicity on potato and tomato. The Ecuadorian A2 isolates from $S$. brevifolium and S. tetrapetalum generally formed small necrotic spots on potato and tomato leaflets. Some of the isolates repeatedly caused small lesions on both potato (generally $S$. phureja) and tomato, with a little sporulation occurring only on necrotic tissue. These lesions rarely expanded beyond $2 \mathrm{~cm}$ in diameter and contrasted strikingly with the large, heavily sporulating lesions caused by potato and tomato isolates on their respective hosts. Host specificity between potato and tomato isolates also occurs in Ecuador, but differences measured with the detached leaf test are small and quantitative (26). The A2 isolates caused actively sporulating lesions on $S$. tetrapetalum and $S$. brevifolium after 7 days. Lesions occupied the entirety of the small leaflets of these species, and abundant sporulation occurred on green tissue. Isolates from potato and tomato usually caused no visible symptoms, but occasionally resulted in necrotic flecking on either S. tetrapetalum or S. brevifolium.

Metalaxyl resistance. Most Ecuadorian A2 isolates almost covered the control plate ( $85 \mathrm{~mm}$ in diameter) after 1 week, while on the $5-\mu \mathrm{g} / \mathrm{ml}$ concentration, growth varied between 0 and $80 \%$ of the controls. At $100 \mu \mathrm{g} / \mathrm{ml}$, none of the isolates had grown at all after 7 days of incubation. Thus, none of the isolates was resistant to metalaxyl, although 17 were classified as intermediately resistant.

\section{DISCUSSION}

The lesions and epidemics seen on S. brevifolium and S. tetrapetalum strongly resembled those of late blight on potatoes, but nevertheless, our first concern when we discovered this disease was whether it was really due to $P$. infestans. Our genetic analyses and observations regarding host range are consistent with the hypothesis that this population is more similar to $P$. infestans than to any other known species of Phytophthora. The population is morphologically indistinguishable from $P$. infestans and has the same ITS2 sequence as $P$. infestans, $P$. mirabilis, and $P$. phaseoli. The A2 population in Ecuador can be distinguished from $P$. phaseoli based on sporangia form and oospore formation ( $P$. phaseoli is homothallic) and from $P$. mirabilis based on host range. The isolates we studied attack plants within the same genus as potato and tomato, and some isolates weakly attack both of these cultivated hosts. The primary hosts of $P$. mirabilis and $P$. phaseoli are not closely related to the genus Solanum. Nonetheless, the Ecuadorian A2 population differs from $P$. infestans based on RFLP fingerprint, Pep genotype, mtDNA haplotype, and primary host. Therefore, subsequent genetic analyses, especially quantitative assessment of gene flow, 
may eventually warrant the description of a new species of Phytophthora for the A2 isolates of Ecuador. This type of analysis was recently used to demonstrate that $P$. infestans and $P$. mirabilis are different species (18).

Lack of sexual recombination in the A2 population from $S$. brevifolium and $S$. tetrapetalum is supported by low genetic diversity (two genotypes from 26 isolates), the apparent absence of similar genotypes with the A1 mating type, and heterozygosity at the Pep locus for all individuals. Therefore, if this population is $P$. infestans, it represents the third, clonally propagated, host-specific population of $P$. infestans to be identified in Ecuador to date. Earlier studies demonstrated that tomatoes in Ecuador are attacked by the clonal lineage US-1 (26) and potatoes by the clonal lineage EC-1 (10). Following a suggested nomenclature (11) and until more thorough taxonomic studies can be done, we designate the A2 population attacking $S$. brevifolium and $S$. tetrapetalum as EC-2 of the species $P$. infestans.

At this point, we included the isolates from Nono in the same clonal lineage as the other Ecuadorian A2 isolates, even though they differ by three RFLP bands. We used conventional nomenclature $(11,14)$ to identify the Nono genotype as EC-2.1, within the clonal lineage EC-2. This was done because the Nono isolates are identical to the other A2 isolates in all other aspects including morphology, presence of three novel RFLP bands, the Pep 76/100 genotype, and the novel mtDNA haplotype. This approach also seems appropriate at this time because our sample size is small $(n=$ 26) and, therefore, nothing is known about the genetic structure of this population outside our sampling area. Both hosts are fairly common in the Andes, and we assume that this pathogen population exists in other parts of Ecuador and perhaps even in other countries. Further information could lead to a reconsideration of the classification of the Nono subpopulation.

Our studies provide no evidence for gene flow between this A2 population and the A1 populations of $P$. infestans on potato and tomato in Ecuador. Several neutral markers (three RFLP bands, the A2 mating type allele, the Pep 76 allele, and the mtDNA haplotype) and sensitivity to metalaxyl differentiate the A2 clonal lineage from populations attacking potato and tomato $(10,26)$. Absence of a common host in nature could provide the principal barrier to gene flow, but low sexual compatibility may also be involved. We paired some A2 isolates with A1 isolates from potato and tomato and then visually examined about 200 oospores per cross with light microscopy. Approximately $25 \%$ of the oospores appeared well developed in the crosses with A1 isolates from potato. Oospores were less abundant, and less than $10 \%$ were well developed in the crosses with A1 isolates from tomato. We do not know if oospores that appear viable would produce viable progeny or if these progeny would be pathogenic on the hosts of the parent isolates. Nonetheless, the potential for gene flow between this A2 population and A1 populations on potato and tomato deserves further examination. Transfer of the A2 allele to potato or tomato populations could have major epidemiological consequences.

It is difficult to speculate on the origin of the Ecuadorian A2 population. It is unique and dissimilar to other known populations of $P$. infestans, but, as we mentioned earlier, studies done to date have focused on the potato and tomato populations of $P$. infestans and not populations attacking alternative hosts. Therefore, the unique character of the Ecuadorian A2 population may be due, at least in part, to sampling bias. Examination of non-tuber-bearing species of Solanum in other parts of the world may lead to the discovery of new genotypes of P. infestans or closely related Phytophthora species. These could provide links between the Ecuadorian A2 population and the well-studied populations of $P$. infestans that attack potato and tomato.

In spite of sampling problems, it appears unlikely that the Ecuadorian A2 population arrived in Ecuador as part of either one of the two main migrations of $P$. infestans that have been described to date (13). These two migrations are well documented and the

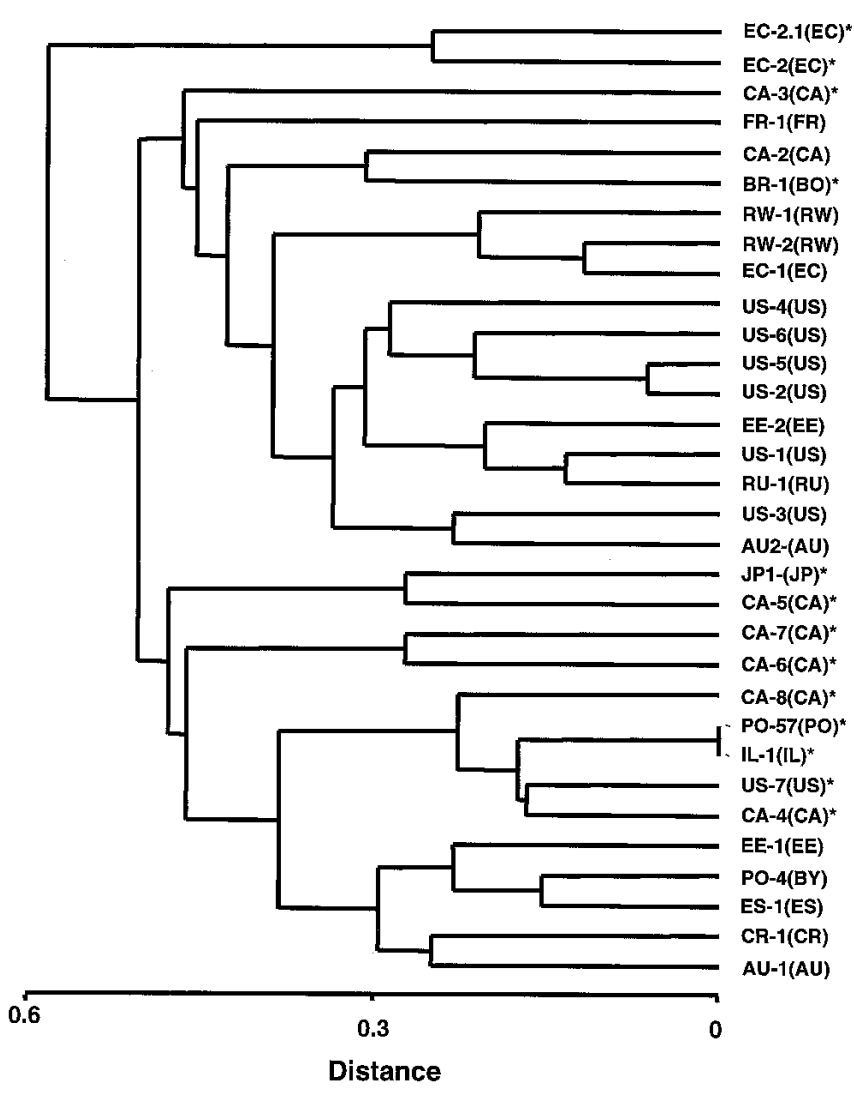

Fig. 3. Cluster analysis of genotypes of Phytophthora infestans coming from a published database representing putatively clonal populations worldwide (11) and two Phytophthora genotypes (EC-2 and EC-2.1) coming from two Ecuadorian wild hosts, Solanum tetrapetalum and S. brevifolium. The analysis is based on a distance coefficient (Jaccard) for multilocus genotypes consisting of restriction fragment length polymorphism fingerprint with the RG57 probe, mating type, and dilocus alloenzyme genotype. Genotype labels are the International Organization for Standardization (ISO) two-letter country code plus a unique number (11). Those labels followed by an asterisk indicate the A2 mating type.

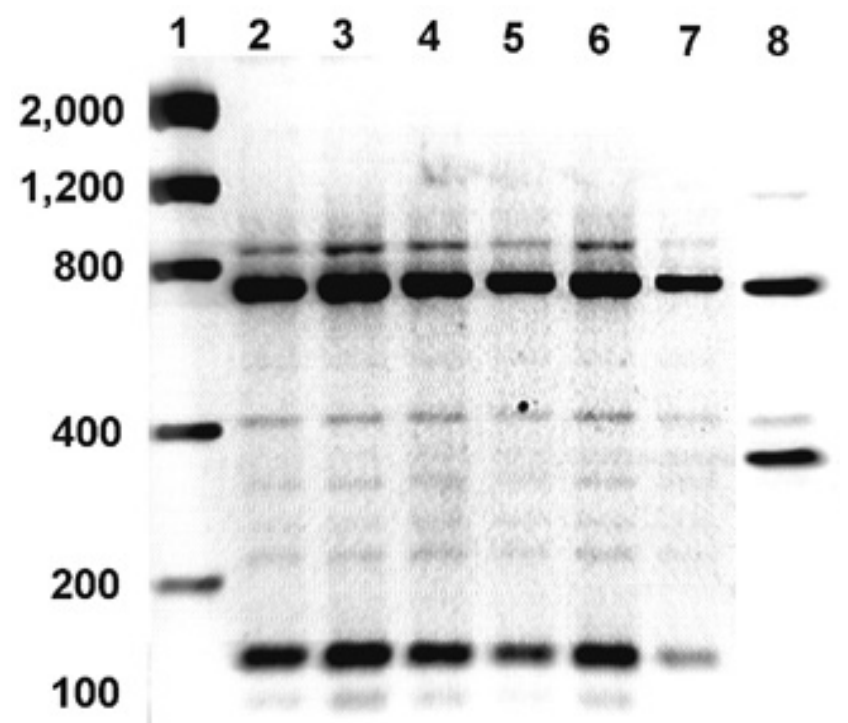

Fig. 4. Pattern of bands produced after polymerase chain reaction amplification with primer set 2 and digestion with $M s p$ I for previously described mitochondrial DNA (mtDNA) haplotypes of Phytophthora infestans (20). Lane 1, DNA ladder (numbers are the approximate size in base pairs); lanes 2 to 7, Phytophthora isolates from Solanum brevifolium and S. tetrapetalum; and lane 8, mtDNA haplotype Ia or IIb of P. infestans. 
genotypes involved are not related to the Ecuadorian A2 genotypes. Thus, if the Ecuadorian A2 population did originate in Mexico, it must have come to Ecuador via another migration. How and when this may have happened is unclear. Therefore, the possibility that the A2 population is indigenous to Ecuador cannot be eliminated at this time.

\section{LITERATURE CITED}

1. Andrivon, D. 1996. The origin of Phytophthora infestans populations present in Europe in the 1840s: A critical review of historical and scientific evidence. Plant Pathol. 45:1027-1035.

2. Carter, D. A., Archer, S. A., and Buck, K. W. 1990. Restriction fragment length polymorphisms of mitochondrial DNA of Phytophthora infestans. Mycol. Res. 94:1123-1128.

3. Caten, C. E., and Jinks, J. L. 1968. Spontaneous variability of single isolates of Phytophthora infestans. I. Cultural variation. Can. J. Bot. 46: 329-348.

4. Colon, L. T., and Budding, D. J. 1988. Resistance to late blight (Phytophthora infestans) in ten wild Solanum species. Euphytica S:77-86.

5. Correll, D. S. 1962. The Potato and Its Wild Relatives. Section Tuberarium of the Genus Solanum. Texas Research Foundation, Renner, TX.

6. Davis, B. J. 1964. Disc electrophoresis-11. Method and application to human serum proteins. Ann. N.Y. Acad. Sci. 121:404-427.

7. DePaulo, J. J., and Powell, C. A. 1995. Extraction of double-stranded RNA from plant tissues without the use of organic solvents. Plant Dis. 79:246-248.

8. Drenth, A., Goodwin, S. B., Fry, W. E., and Davidse, L. C. 1993. Genotypic diversity of Phytophthora infestans in the Netherlands revealed by DNA polymorphisms. Phytopathology 83:1087-1092.

9. Erwin, D. C., and Ribeiro, O. K. 1996. Phytophthora Diseases Worldwide. The American Phytopathological Society, St. Paul, MN.

10. Forbes, G. A., Escobar, X. C., Ayala, C. C., Revelo, J., Ordoñez, M. E., Fry, B. A., Doucett, K., and Fry, W. E. 1997. Population genetic structure of Phytophthora infestans in Ecuador. Phytopathology 87:375-380.

11. Forbes, G. A., Goodwin, S. B., Drenth, A., Oyarzun, P., Ordoñez, M. E., and Fry, W. E. 1998. A global marker database for Phytophthora infestans. Plant Dis. 82:811-818.

12. Fry, W. E., Goodwin, S. B., Dyer, A. T., Matuszak, J. M., Drenth, A., Tooley, P. W., Sujkowski, L. S., Koh, Y. J., Cohen, B. A., Spielman, L. J., Deahl, K. L., Inglis, D. A., and Sandlan, K. P. 1993. Historical and recent migrations of Phytophthora infestans: Chronology, pathways, and implications. Plant Dis. 77:653-661.

13. Goodwin, S. B. 1997. The population genetics of Phytophthora. Phytopathology 87:462-473.

14. Goodwin, S. B., Cohen, B. A., Deahl, K. L., and Fry, W. E. 1994. Mi- gration from northern Mexico as the probable cause of recent genetic changes in populations of Phytophthora infestans in the United States and Canada. Phytopathology 84:553-558.

15. Goodwin, S. B., Cohen, B. A., and Fry, W. E. 1994. Panglobal distribution of a single clonal lineage of the Irish potato famine fungus. Proc. Natl. Acad. Sci. U.S.A. 91:11591-11595.

16. Goodwin, S. B., and Drenth, A. 1997. Origin of the A2 mating type of Phytophthora infestans outside Mexico. Phytopathology 87:992-999.

17. Goodwin, S. B., Drenth, A., and Fry, W. E. 1992. Cloning and genetic analyses of two highly polymorphic, moderately repetitive nuclear DNAs from Phytophthora infestans. Curr. Genet. 22:107-115.

18. Goodwin, S. B., Legard, D. E., Smart, C. D., Levy, M., and Fry, W. E. 1999. Gene flow analysis of molecular markers confirms that Phytophthora mirabilis and $P$. infestans are separate species. Mycologia 91:796810.

19. Goodwin, S. B., Spielman, L. J., Matuszak, J. M., Bergeron, S. N., and Fry, W. E. 1992. Clonal diversity and genetic differentiation of Phytophthora infestans populations in northern and central Mexico. Phytopathology 82:955-961.

20. Griffith, G. W., and Shaw, D. S. 1998. Polymorphisms in Phytophthora infestans: Four mitochondrial haplotypes are detected following PCR amplification of DNA from pure cultures or from host lesions. Appl. Environ. Microbiol. 64:4007-4014.

21. Hohl, H. R. 1991. Nutrition. Pages 53-83 in: Advances in Plant Pathology-Vol. 7. Phytophthora infestans, the Cause of Late Blight of Potato. D. S. Ingram and P. H. Williams, eds. Academic Press, London.

22. Hohl, H. R., and Iselin, K. 1984. Strains of Phytophthora infestans from Switzerland with A2 mating type behaviour. Trans. Br. Mycol. Soc. 83: 529-530.

23. Ko, W. H. 1994. An alternative possible origin of the A2 mating type of Phytophthora infestans outside Mexico. Phytopathology 84:1224-1227.

24. Niederhauser, J. S. 1991. Phytophthora infestans: The Mexican connection. Pages 25-45 in: Phytophthora. J. A. Lucas, R. C. Shattock, D. S. Shaw, and L. R. Cooke, eds. Cambridge University Press, Cambridge.

25. Oyarzun, P. J., Ordoñez, M. E., and Forbes, G. A. 1997. First report of Phytophthora infestans A2 mating type in Ecuador. Plant Dis. 81:311.

26. Oyarzun, P. J., Pozo, A., Ordoñez, M. E., Doucett, K., and Forbes, G. A. 1998. Host specificity of Phytophthora infestans on tomato and potato in Ecuador. Phytopathology 88:265-271.

27. Spielman, L. J. 1991. Isoenzymes and population genetics of Phytophthora infestans. Pages 231-241 in: Phytophthora. R. C. Shattock, D. S. Shaw, L. R. Cook, and J. A. Lucas, eds. Cambridge University Press, Cambridge.

28. Tooley, P. W., Bunyard, B. A., Carras, M. M., and Hatziloukas, E. 1997. Development of PCR primers from internal transcribed spacer region 2 for detection of Phytophthora species infecting potatoes. Appl. Environ. Microbiol. 63:1467-1475. 